\title{
Financial interests of patient organisations contributing to technology assessment at England's National Institute for Health and Care Excellence: policy review
}

\author{
Kate L Mandeville, ${ }^{1}$ Rosie Barker, ${ }^{2}$ Alice Packham, ${ }^{2}$ Charlotte Sowerby, ${ }^{3}$ Kielan Yarrow, ${ }^{4}$ \\ Hannah Patrick ${ }^{5}$
}

${ }^{1}$ Centre for Health Economics in London, London School of Hygiene \& Tropical Medicine, London WC1H 9SH, UK

${ }^{2}$ University of Oxford, Oxford OX1 2JD, UK

${ }^{3}$ Royal Free Hospital, London NW3 2QG, UK

${ }^{4}$ Department of Psychology, City University, London EC1V OHB, UK

${ }^{5}$ Lewisham and Greenwich NHS Trust, London, UK

Correspondence to:

K Mandeville

kate.mandeville@lshtm.ac.uk (or @mandevillek on Twitter ORCID 0000-0002-5525-1574) Additional material is published online only. To view please visit the journal online.

Cite this as: BMJ 2019;364:k5300 http://dx.doi.org/10.1136/bmi.k5300

Accepted: 26 November 2018

\section{ABSTRACT}

OBJECTIVE

To investigate the prevalence of financial interests among patient organisations contributing to health technology assessment at the National Institute for Health and Care Excellence (NICE) in England and the extent to which NICE's disclosure policy ensures that decision making committees are aware of these interests.

\section{DESIGN}

Policy review using accounts, annual reports, and websites of patient organisations; payments declared by pharmaceutical manufacturers on their websites and a centralised database (Disclosure UK); declarations of interests by nominated representatives of patient organisations; and responses from patient organisations.

\section{SETTING}

Appraisals of medicines and treatments (technologies) for use in the English and Welsh National Health Service.

\section{PARTICIPANTS \\ 53 patient organisations contributing to $41 \mathrm{NICE}$ technology appraisals published in 2015 and 2016, with 117 separate occasions that a patient organisation contributed to the appraisal of a technology.}

\section{MAIN OUTCOME MEASURES}

Prevalence of specific interests (that is, funding from manufacturer(s) of a technology under appraisal or competitor products); proportion of specific interests of which NICE's decision making committees were aware; proportion of unknown specific interests for which disclosure was not required by NICE's policy

\section{WHAT IS ALREADY KNOWN ON THIS TOPIC}

Patient organisations are increasingly involved in health technology assessment Concerns have been raised about funding received by patient organisations from pharmaceutical manufacturers

Whether this funding is relevant among patient organisations contributing to health technology assessment is not known

\section{WHAT THIS STUDY ADDS}

Funding by manufacturers of technologies under appraisal and competitor products is highly prevalent among patient organisations contributing to health technology assessment in England

Financial interests held by both individuals and organisations contributing to health technology assessment require systematic identification to improve transparency

\section{RESULTS}

$38 / 53(72 \%)$ patient organisations had accepted funding from the manufacturer(s) of a technology or a competitor product in the same year that they had contributed to the appraisal of that technology or the previous year. Specific interests were present on 92/117 (79\%) occasions that patient organisations contributed to appraisals in 2015 and 2016. NICE's decision making committees were aware of less than a quarter of specific interests $(30 / 144 ; 21 \%)$. For nearly two thirds of the specific interests not known to committees $(71 / 114 ; 62 \%)$, disclosure by patient organisations was not required by NICE's policy.

\section{CONCLUSIONS}

Financial interests are highly prevalent among patient organisations contributing to health technology assessment. NICE should review its disclosure policy to ensure that decision making committees are aware of all relevant interests.

\section{Introduction}

Recent studies have highlighted conflicts of interest held by patient organisations and their potential influence on public policy. ${ }^{1-4}$ An investigation of 104 of the largest patient organisations in the US found that at least $83 \%$ received financial support from pharmaceutical, device, and/or biotechnology companies. $^{2}$ Another survey of 289 US patient organisations found that these organisations derived an average of $45 \%$ of their income from pharmaceutical, device, and/or biotechnology companies. ${ }^{3}$ Three quarters of organisations that responded to this survey had taken part in policy or advocacy activities in the previous fiscal year, with two out of three receiving industry funding in the same year as their policy/ advocacy activities. Studies examining the policy activities of patient organisations have found evidence of relevant undeclared pharmaceutical industry funding in several forums, including the US Food and Drug Administration (FDA), the US Centers for Disease Control and Prevention (CDC), and the European Medicines Agency. ${ }^{145}$

Patient organisations have been defined as "public charities whose primary mission is to combat a particular disease or disability or to work towards improving the health and well-being of a particular population via activities including (but not limited to) providing patient education and services, funding research, and/or engaging in outreach advocacy." ${ }^{2}$ In times of increasing financial pressure on patient organisations, funding from industry may be welcomed 
to sustain important charitable activities. When the interests of funders overlap with the charity's area of work, however, this can give rise to institutional conflicts of interest in which "an institution's own financial interests or the interests of its senior officials pose risks to the integrity of the institution's primary interests and missions." 67 Such conflicts of interest hold considerable reputational risk and may damage the public's confidence in the independence of patient organisations and policy decisions. ${ }^{8}$ Mitigation strategies include voluntary or mandatory disclosure of funding sources, codes of practice, conditions on funding from industry, and refusal to accept any industry funding. ${ }^{2}$

An important area of advocacy for patient organisations is that of decisions on public coverage of medicines and treatments, often undertaken by health technology assessment (HTA) agencies. HTA agencies are increasingly seeking to involve patients in their decision making processes, with participation now standard in agencies across North America, Europe, Asia, and Australasia. ${ }^{9-14}$ Incorporating patient perspectives into HTA provides unique information about the impact of the condition or treatment that may not be available elsewhere, leading to more informed, responsive, and legitimate decisions. ${ }^{15} 16$ HTA agencies often work with patient organisations to recruit or represent patients, and surveys consistently show that HTA agencies most commonly engage with patient organisations rather than with individual patients or members of the public. ${ }^{10-1317} 18$ At the National Institute for Health and Care Excellence (NICE) in England, patient organisations are most routinely involved in the programme for assessing new and existing medicines and treatments known as technology appraisal. The English and Welsh National Health Services (NHS) are legally obliged to provide any technologies recommended by NICE's technology appraisal. ${ }^{19}$ To date, NICE has asked patient organisations to declare potential interests only if an organisation's representative is nominated to give evidence to a decision making committee. ${ }^{20} \mathrm{In}$ this case, representatives should consider declaring any funding received by their organisation from the manufacturer of the technology under appraisal or a competitor product as an indirect specific interest. To review the effectiveness of this policy, we investigated the prevalence of interests-both declared and undeclared-among patient organisations contributing to the technology appraisal programme at NICE.

\section{Methods}

We collated a list of patient organisations contributing to technology appraisal guidance over two years of the programme. To do this, we used a publicly available list of NICE's decisions (https://www. nice.org.uk/about/what-we-do/our-programmes/ nice-guidance/nice-technology-appraisal-guidance/ summary-of-decisions) to identify all technology appraisals published between 1 January 2015 and 31 December $2016(n=97) .^{21}$ Technology appraisals can be discussed by the decision making committee at several meetings during the development process, with most evidence presented at the initial discussion. We therefore excluded any technology appraisal that had its initial discussion at a meeting earlier than 2015 . We also excluded any technology appraisals that were reappraisals of technologies as part of the Cancer Drugs Fund, ${ }^{22}$ as well as any that were subsequently withdrawn, terminated, or replaced with later guidance (see figure 1).

Two authors (KM and HP) reviewed the documents for each technology appraisal publicly available on the NICE website (www.nice.org.uk) to identify any patient organisations that had contributed to that technology appraisal. Five main types of contributions exist (https://www.nice.org.uk/about/what-we-do/ our-programmes/nice-guidance/nice-technologyappraisal-guidance): commenting on the draft scope, which defines the patient population, comparator technologies, and outcomes covered by the appraisal; submitting written evidence to the decision making committee that will be considered alongside clinical and economic evidence; nominating a patient expert to provide written and oral evidence to the committee; nominating a clinical expert to provide written and oral evidence to the committee; and responding to consultations on draft guidance (usually held only when NICE is minded not to recommend a technolgy). Contributing patient organisations may also appeal the final recommendation made by NICE. Technology appraisals may assess multiple drugs or treatments at the same time. We therefore counted each occasion that a patient organisation contributed to a technology in a technology appraisal as a separate event. For each occasion, we noted the manufacturer of the technology under appraisal, as well as manufacturer(s) of any competitor products as designated by NICE in the publicly available matrix document for each technology appraisal.

We then assessed whether patient organisations contributing to the technology appraisal programme had declared any interests. All people attending committee meetings on behalf of an organisation are asked to declare any interests that might directly benefit them as individuals, as well as any relevant interests held by their organisation as indirect interests. ${ }^{20}$ For technology appraisals, patient experts are ideally people who have the condition and, where possible, have used the medicine or treatment under appraisal. Patient organisations may identify such people from their volunteers or beneficiary networks. However, patient experts are often employees, medical directors, or trustees of a patient organisation, with expertise on a condition gathered from their personal or professional experience. We restricted our analysis to these individuals, as other patient experts may not have considered that they were representing an organisation. Declarations of interests should occur at two points: a written declaration as part of a standard nomination form filled in by all experts, which may influence their selection for committee meetings; and 


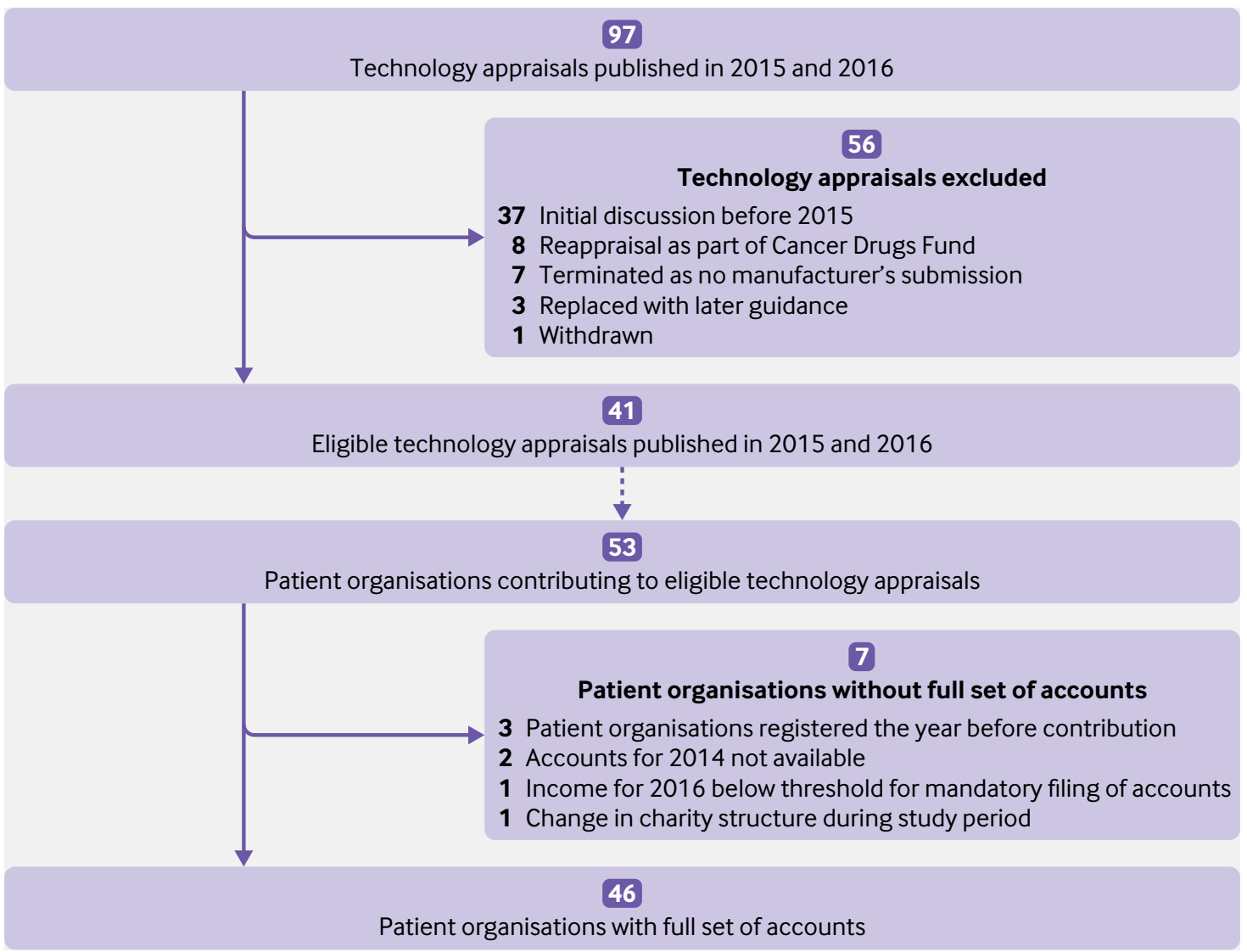

Fig 1 | Flow of technology appraisals and patient organisations

an oral declaration made by all experts at the start of any committee meetings. To investigate the first of these, we requested nomination forms held by NICE for all patient experts nominated for the eligible technology appraisal (see supplementary file for version of nomination form used during study period). One author with access to NICE's internal records (HP) reviewed all available forms, noting whether the patient expert was an employee, trustee, or medical director of the nominating patient organisation and whether any indirect specific interests were declared (funding received by the organisation from the manufacturer(s) of the technology under appraisal or competitor products). To investigate oral declarations, two authors (KM and CS) reviewed minutes of the first committee meeting at which each technology appraisal was discussed, noting the same aspets as above. All minutes are publicly available on the NICE website (https://www.nice.org.uk/Get-Involved/Meetingsin-public/Technology-Appraisal-Committee). Any differences or ambiguous cases were discussed between authors until resolution.

We then searched for declared pharmaceutical industry funding in relevant years. This was the year in which a patient organisation had contributed to a technology appraisal (that is, 2015 or 2016) and the previous year (2014 or 2015). This time period is in line with NICE's policy, which requires an initial declaration of interests to cover the preceding 12 month period. ${ }^{20}$ We searched the Association of British Pharmaceutical Industry (ABPI)'s Disclosure UK database (http://www.abpi.org.uk/ethics/ethicalresponsibility/disclosure-uk). The ABPI's Code of Practice requires pharmaceutical manufacturers to disclose any financial support to healthcare professionals and organisations (including patient organisations), with data from 2015 available on the database. ${ }^{23}$ Two authors (KM and HP) searched the database for payments to all identified patient organisations in 2015 and 2016, extracting the year, amount, and manufacturer. We included payments to employees, medical directors, or trustees of that organisation and all payments listed under the organisation's name even if the listed address was different from the registered office. We excluded payments if the organisation's name indicated a different jurisdiction (for example, [patient organisation name] Northern Ireland) and this was a charity separately registered with the appropriate charity regulator (see below). Results were compared between authors, with discussion to resolve any discrepancies. As Disclosure UK is not yet comprehensive (http://www.abpi.org.uk/ethics/ ethical-responsibility/disclosure-uk/explore-thedata-further/), we also searched the websites of all relevant manufacturers for disclosures of payments to patient organisations in 2014, 2015, and 2016. We converted currencies into pounds sterling where 
necessary, using historical exchange rates from xe.com for 1 January 2014, 2015, and 2016.

Following the approach of McCoy et al, two authors (CS and AP) also reviewed the annual accounts (and accompanying annual reports where available) of patient organisations in relevant years to identify pharmaceutical industry funding. ${ }^{2}$ If accounts were not available on the organisation's website, we searched the website of the appropriate charity regulator-that is, the Charity Commission for England and Wales (https://www.gov.uk/government/organisations/ charity-commission) or the Scottish Charity Regulator (https://www.oscr.org.uk). Charities in the UK can have different financial years, so we defined 2014 accounts as having a financial year ending between 1 July 2014 and 30 June 2015, 2015 accounts between 1 July 2015 and 30 June 2016, and 2016 accounts between 1 July 2016 and 30 June 2017. We noted any reported funding from the pharmaceutical industry, including amount and manufacturer, and calculated the proportion of total funding that this represented for the organisation. Accounting standards for UK charities recommend recording substantial in-kind contributions (for example, providing catering for an event or printing promotional materials) with their approximate value. Another author (KM) reviewed the extracted data and compared any discrepancies with the primary data sources.

Two authors (RB and CS) also searched the websites of all patient organisations for any mention of pharmaceutical industry funding, including likely inkind contributions (such as "we thank X for supporting our event”). We noted the manufacturer, amount, and year of donation where available. We also searched for any policies related to pharmaceutical industry funding.

Discrepancies or lack of detail in these data sources prompted us to follow the approach of Perehudoff and Alves by contacting all patient organisations by email or website enquiry form as a final step. ${ }^{5}$ This allowed us to validate the findings from the previous steps, as well as to consult patient organisations on our proposed recommendations. We sent one reminder email after one week.

We pooled evidence of pharmaceutical industry funding from annual accounts/reports, websites, manufacturers' disclosures, declarations of interests, and responses from patient organisations. We took the highest amount of funding from each manufacturer declared across all data sources to calculate total funding. For each patient organisation, we then noted whether it had accepted funding from the manufacturer(s) of a technology or competitor product(s) in the same year that it had contributed to the appraisal of that technology or the previous year, which NICE would consider a specific interest. As patient organisations can contribute to several technology appraisals, we did the same for each occasion that an organisation had contributed to a technology appraisal. If a specific interest was identified, we noted whether the NICE committee was aware of this interest through either written or oral declaration by the representative of the patient organisation. For the three occasions in which both nomination form (written declaration) and meeting minutes (oral declaration) were missing, we assumed that committees were aware of any interests. For specific interests of which committees were unaware, we noted whether this was because disclosure had not been required by NICE's policy (that is, contributions from patient organisations other than nomination of experts).

To examine whether specific interests of unknown to NICE's committees had an effect on decisions, we did a logistic regression of NICE's decision for each technology (that is, recommended or not recommended for use in the NHS) against the presence of unknown specific interests. The results were inconclusive, but power was low, so we omitted the analysis from this report.

\section{Patient and public involvement statement}

The Public Involvement Programme, which supports involvement of patients, carers, and the public in NICE's activities, advised on the design and conduct of this study. We also consulted with patient organisations about our proposed recommendations, and we plan to disseminate our findings to these organisations by email after publication. Individual patients and members of the public were not directly involved in the conduct of this study.

\section{Results}

NICE published 97 technology appraisals in 2015 and 2016. We included 41 of these in the analysis (see figure 1 for reasons for exclusion). All but two technology appraisals received contributions from at least one patient organisation, with 53 different organisations identified (fig 1). Twenty three (43\%) of these contributed to multiple technology appraisals over the two years (range one to six), with 117 occasions in total when a patient organisation had contributed to a technology appraisal. In terms of type of contribution, patient organisations most frequently submitted evidence and nominated patient experts (table 1$)$. Two thirds $(52 / 76 ; 68 \%)$ of patient experts nominated by patient organisations were employees (including chief executives), trustees, or medical directors of that organisation.

Table 2 summarises evidence of pharmaceutical industry funding from patient organisations' annual accounts/reports, websites, Disclosure UK, individual manufacturers' disclosures, declarations of interests, and patient organisations' responses. The income of patient organisations ranged from less than $£ 20000$ (€22 000; \$25 000) to more than $€ 119$ million between 2014 and 2016. The percentage of income from pharmaceutical industry funding ranged from less than $1 \%$ to one organisation deriving nearly $70 \%$ of its income from three manufacturers. Wide discrepancy existed between these data sources, including amounts of funding and named manufacturer(s). Individual manufacturers' disclosures provided the most complete 


\begin{tabular}{|c|c|}
\hline Type of contribution & No of occasions/total occasions (\%) \\
\hline Comments on draft scope* & $50 / 117(43)$ \\
\hline Submission of written evidencet & $78 / 117(67)$ \\
\hline Nomination of patient expert(s)† & $76 / 117(65)$ \\
\hline Nomination of clinical expert(s)† & $9 / 117(8)$ \\
\hline Comments on draft guidancet & $47 / 81 \neq(58)$ \\
\hline Appeal against final recommendation & $0 / 15 \neq(0)$ \\
\hline
\end{tabular}

picture, despite being available for only just over a third of manufacturers $(31 / 87 ; 36 \%)$. Less than half of manufacturers in this study $(42 / 87 ; 48 \%)$ submitted data to Disclosure UK in 2015 and 2016, limiting its usefulness. Along with lack of completeness, the database seems to have no unique identifier for patient organisations (such as registered charity number) and payments were often not consistent with those declared on manufacturers' websites. Inconsistency between written and oral declarations was present on 22/36 (61\%) occasions. Contacting patient organisations resolved discrepancies between data sources in only a fifth of cases, with 11 (21\%) organisations able to clarify manufacturers' funding. Seventeen (32\%) organisations replied but did not want to provide data, and 27 (51\%) did not respond.

When we pooled all the evidence, more than two thirds $(38 / 53 ; 72 \%)$ of patient organisations held specific interests (that is, funding from the manufacturer(s) of a technology or a competitor product in the same year as the organisation contributed to that technology's appraisal or the previous year) (table 3). As patient organisations often contributed to multiple technology appraisals, we also examined evidence of pharmaceutical industry funding for each occasion that a patient organisation contributed to technology appraisals. Specific interests were present in almost four out of five $(92 / 117 ; 79 \%)$ occasions that patient organisations contributed to technology appraisals in 2015 and 2016.

After review of written and oral declarations of interests, we found that NICE's decision making committees were aware of less than half (30/73; 41\%) of all declarable specific interests (table 3). For nearly two thirds $(71 / 114 ; 62 \%)$ of the specific interests unknown to committees, declaration was not required by NICE's disclosure policy (that is, contributions from patient organisations other than nomination of representatives as patient experts). Overall, NICE committees were aware of less than a quarter $(30 / 114$, $21 \%$ ) of all specific interests identified (both declarable and non-declarable under current policy). Nearly all representatives who declared specific interests on behalf of their organisation at nomination stage were invited to attend the first committee meeting, with no difference between the proportions of those declaring interests and attending and those declaring no interests and attending (20/21 v 23/25; Fisher's exact $\mathrm{P}=1)$. All representatives who declared specific interests on behalf of their organisation at the start of committee meetings were allowed to remain in the meeting and provide oral evidence.

We identified policies on pharmaceutical industry funding for nearly a third $(16 / 53 ; 30 \%)$ of patient organisations, with two organisations not accepting any funding from manufacturers. Twelve organisations committed to disclosing any funding in annual reports or websites, 11 placed conditions on funding such as a cap on the percentage of income received from industry or from one manufacturer, and three organisations had specific clauses for policy and HTA activities.

\section{Discussion}

Virtually all NICE's appraisals of medicines and treatments for use in the NHS in 2015 and 2016 received contributions from patient organisations, with many such organisations contributing to multiple appraisals. More than two thirds of patient organisations had accepted funding from the manufacturer(s) of a technology or a competitor product(s) in the same year that that they had contributed to the appraisal of that technology or in the previous year. NICE's decision making committees were aware of less than a quarter of all specific interests identified. For almost two thirds of the specific interests unknown to committees, disclosure by patient organisations was not required by NICE's policy.

\begin{tabular}{|c|c|c|c|c|}
\hline \multirow[b]{2}{*}{ Funding indicator } & \multicolumn{4}{|l|}{ Data source } \\
\hline & Accounts/annual reports/websites* & Disclosure UK† & Individual manufacturers' disclosures & Total‡ \\
\hline Median (IQR) income $\S, f$ & $1833572(341323-3857722)$ & - & - & - \\
\hline $\begin{array}{l}\text { Patient organisation reporting pharmaceutical } \\
\text { industry funding in } \geq 1 \text { relevant year }(\%)\end{array}$ & $24 / 53(45)$ & $32 / 53(60)$ & $44 / 53(85[83 ?])$ & $46 / 53(87)$ \\
\hline $\begin{array}{l}\text { Median (IQR) percentage of income from } \\
\text { pharmaceutical industry funding } \S\end{array}$ & $0(0-1)$ & $.01(0-0.3)$ & $1.9(0.3-12.5)$ & $3.1(0.1-24.6)$ \\
\hline $\begin{array}{l}\text { Median (IQR) total amount of pharmaceutical } \\
\text { industry funding§, } f\end{array}$ & $0(0-25750)$ & $283(0-5120)$ & $37707(2500-135081)$ & $38754(6375-105485)$ \\
\hline Median (IQR) No of funding manufacturers§ & $0(0-2)$ & $0.5(0-1)$ & $1.5(0.5-2.7)$ & 2. $(0.5-5.5)$ \\
\hline \multicolumn{5}{|c|}{ 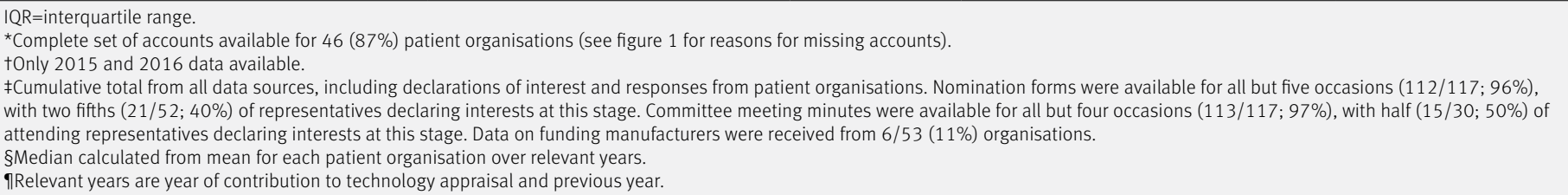 } \\
\hline
\end{tabular}




\begin{tabular}{|c|c|c|c|}
\hline Proportion & $\begin{array}{l}\text { Funding from } \geq 1 \text { manufacturer(s) of } \\
\text { technology under appraisal }\end{array}$ & $\begin{array}{l}\text { Funding from } \geq 1 \text { manufacturer(s) of } \\
\text { competitor product(s) }\end{array}$ & $\begin{array}{l}\text { Total specific interests } \\
\text { present* }\end{array}$ \\
\hline Patient organisations with specific interests & $34 / 53(64)$ & $34 / 53(64)$ & $38 / 53(72)$ \\
\hline Occasions with specific interests present & $73 / 117(62)$ & $71 / 117(61)$ & $92 / 117(9)$ \\
\hline $\begin{array}{l}\text { Specific interests known to NICE's committees out of all declarable } \\
\text { specific interestst }\end{array}$ & $18 / 39(46)$ & $12 / 34(35)$ & $30 / 73(41) \ddagger$ \\
\hline $\begin{array}{l}\text { Specific interests unknown to NICE's committees owing to NICE's } \\
\text { disclosure policy out of all unknown specific interestst§ }\end{array}$ & $34 / 55(62)$ & $37 / 59(63)$ & $71 / 114(62) \ddagger$ \\
\hline $\begin{array}{l}\text { Specific interests known to NICE's committees out of all specific } \\
\text { interests identified }\end{array}$ & $18 / 73(25)$ & $12 / 71(17)$ & $30 / 144(21) \neq$ \\
\hline \multicolumn{4}{|c|}{$\begin{array}{l}\text { *NICE considers both funding from manufacturer(s) of technology under appraisal and manufacturers of competitor products as specific interests. } \\
\text { tDenominator includes only specific interests in which nominated patient experts were employees, trustees, or medical directors of patient organisations. These people would be expected to } \\
\text { declare their organisation’s interests as indirect interests. } \\
\text { fEach specific interest counted separately, so values are sum of first two columns rather than number of occasions. } \\
\text { SNICE's disclosure policy requires declaration of indirect interests onlv by nominated exnerts as above and not for other tvpes of contributions by patient organisations. }\end{array}$} \\
\hline
\end{tabular}

\section{Strengths and limitations of study}

The main strength of this study is the systematic and comprehensive search for relevant interests of patient organisations. Despite these efforts, incomplete and inconsistent reporting by both patient organisations and manufacturers means that uncertainty remains about the extent to which these results reflect the true prevalence of interests. Many organisations did not make specific details of pharmaceutical industry funding (including in-kind contributions) publicly available and did not provide these when contacted directly. Restricting the search to the two year period stipulated by NICE's policy may also have led to under-identification of relevant interests. Although the Canadian Agency for Drugs and Technologies in Health and the Scottish Medicines Consortium also use a two year period for patient representatives, the French Haute Autorité de Santé requires declarations to cover the previous five years. ${ }^{1024-26}$ Furthermore, a recent investigation found evidence of payments by manufacturers to FDA advisors up to eight years after their participation in drug advisory committees. ${ }^{27} \mathrm{~A}$ longer period of investigation, both before and after participation in HTA decisions, might have identified a greater number of relevant interests. Overall, however, the marked prevalence of interests gathered from a highly fragmented disclosure landscape indicates that this study provides a valid baseline assessment. Finally, we assumed that all written declarations of interest were available to NICE's committees; however, if this was not the case, inconsistency between written and oral declarations means that committees may have been unaware of a greater proportion of interests than noted here.

\section{Comparison with other studies}

In a similar study to ours, Abola and Prasad investigated the financial interests of speakers at meetings of the FDA Oncological Drugs Advisory Committee between 2009 and 2014..$^{1}$ One third of patient organisations represented by speakers had received funding from the manufacturer of the drug seeking marketing approval. However, the authors looked only at interests declared during the meeting, rather than exploring other data sources as in our study. A report for Health Action International followed a similar method to this study to examine funding of all patient organisations eligible to work with the European Medicines Agency in 2009 on matters relevant to patients and consumers. ${ }^{5}$ Fifteen of 23 (65\%) patient organisations had received pharmaceutical industry funding between 2006 and 2008, averaging 47-57\% of total income, compared with $87 \%$ of patient organisations and $3 \%$ of income in our sample. The difference in income may be due to the European or international scope of the patient organisations (for example, Alzheimer Europe) or a greater amount of information obtained directly from patient organisations compared with our study. The authors also noted the difficulty in obtaining accurate information on funding through available sources, with only six organisations meeting the European Medicines Agency's financial transparency criteria, and called for a uniform and detailed reporting system. Another relevant study undertook a content analysis of responses to a public consultation on the CDC's guidelines on prescribing of opioids in chronic pain. ${ }^{4}$ The authors found that opposition to the guidelines was significantly more common in both patient and professional organisations that had received funding from manufacturers of opioids, compared with organisations without any industry support. As NICE undertakes a consultation only if a committee is minded not to recommend a treatment, all responses included in this study were supportive of the treatment under appraisal so insufficient variation existed for us to undertake a similar analysis. Other possible source documents were the minutes of committee meetings and written statements from patient organisation, but these follow standard templates without sufficient variation for meaningful analysis. Finally, Jones compared the funding declared on the websites of manufacturers and UK patient organisations a decade ago and identified a similar lack of systematic disclosure by both sectors, with manufacturers more likely to acknowledge relationships than patient organisations. $^{8}$ Although disclosed funding also amounted to only a small proportion of total income, belying concerns about agenda setting, very few patient organisations actively managed this relationship. For example, only a quarter of patient organisations (9/34; $26 \%$ ) had funding policies, nearly the same proportion as in our study conducted 10 years later $(6 / 53 ; 30 \%)$. 
The author concludes that this "shallow approach to transparency" reduces the legitimacy of patient organisations as representatives of patients and carers in the policy process, which can be counteracted by properly executed disclosure. $^{8}$

\section{What this study adds}

This study provides a timely examination of the effectiveness of NICE's policy in identifying relevant relationships with industry among its stakeholders. ${ }^{28}$ It is also one of the first study as far as we are aware to examine the interaction between industry funding and patient organisations in HTA decisions. Although previous studies (including a 2011 systematic review) have described increasing involvement of patients in HTA agencies worldwide, most have recognised the need for greater evaluation. ${ }^{10} 1116$ This study also contributes to the quality standard of Health Technology Assessment International, which states that processes for involvement of patients in HTA should be regularly reflected on and reviewed, with the intent of continuous improvement. ${ }^{11}{ }^{14-16}$ Other authors have noted the limitations of Disclosure UK for investigating payments to healthcare professionals, but this is the first study to our knowledge to report inconsistency with other data sources for payments to healthcare organisations. ${ }^{29} 30$

\section{Policy implications}

NICE has been a pioneer in patient involvement, and the extremely high contribution rate seen here is an indicator of the programme's success. ${ }^{12}{ }^{16}$ Also, interests do not equate to a lack of independence of an organisation. Patient organisations provide much needed services for free in a difficult financial environment. $^{31}$ Manufacturers represent important stakeholders for these organisations, not only for funding but also for advocacy on patient needs. When contributing to public policy, however, transparency about funding sources is critical to allow decision makers to make informed judgments about the relevance of any declared interests. ${ }^{32} 33$ As Newton et al describe, organisations responsible for development and implementation of policy must institutionalise an approach to identify and manage perceived and actual conflicts of interest to maintain public confidence in decision making. ${ }^{33}$ NICE's policy does this on an individual level, but it does not provide a standardised framework for interests held at an institutional level. ${ }^{20}$ We recommend extending this policy to include disclosure standards for patient organisations that contribute to NICE's activities. These standards need to balance maintaining credibility in the objectivity of HTA decisions with overly restrictive measures that discourage patient organisations from participating in HTA. We recommend that patient organisations should be required to declare specific interests when contributing to individual appraisals. For example, the Scottish Medicines Consortium asks patient organisations to provide details of previous pharmaceutical industry funding that accompanies each of their contributions and is updated annually. ${ }^{34}$ Published appraisals include the proportion of income represented by pharmaceutical industry funding for each contributing patient organisation, including the manufacturer of the technology under appraisal. ${ }^{35}$ As NICE's committees were less aware of funding from competitors than from manufacturers, these should be specifically asked about in declarations. Financial interests of committee members related to competitors have led to French legal rulings against decisions by the Haute Autorité de Santé in the past, so such "negative" conflicts of interest should be treated as seriously as more visible "positive" conflicts of interest. $^{26}$ On consultation, patient organisations requested clear guidance with examples of relevant interests that should be declared to support consistency of disclosure. Any declared funding can then be recorded in the published guidance. NICE could also ask manufacturers to disclose any funding to patient organisations as part of committee meetings, using the same information as for Disclosure UK but providing an accessible record in the public minutes. Similar disclosure by manufacturers for all patient organisations has been a legal requirement at the Haute Autorité de Santé since $2010 .^{12}$ As good practice, NICE could encourage contributing patient organisations to have a policy on pharmaceutical industry funding, ideally with a framework for policy/ HTA activities. NICE should monitor this extended conflicts of interest policy and detail the consequences of non-compliance, which are absent from the current policy. ${ }^{20}$ We have shared these recommendations with NICE, which will review its policy in 2019.

To improve transparency on pharmaceutical industry funding, we recommend that more patient organisations should disclose funding sources with amounts on websites and in annual reports. Senior management should ensure that any individuals representing the organisation in policy activities are prepared to declare relevant interests. We recognise that many patient organisations would consider advocating for a specific product to be part of their aim to improve access to innovative treatments, but a policy of not accepting funding from manufacturers of endorsed technologies for at least one year before and after these activities would enhance their independence. We also recommend that more manufacturers should make full use of Disclosure UK, with the discrepancy between the database and declarations elsewhere meriting a more systematic analysis. The impact of these recommendations should be audited in three years. A continued lack of improvement could support a move from voluntary to mandatory disclosure of pharmaceutical industry funding, as is the case in the US and several European countries. ${ }^{82636}$ For example, France now requires manufacturers to disclose all payments to patient organisations in a centralised public database. ${ }^{2636}$ Declarations of interest for all contributors to the Haute Autorité de Santé are also publicly available and regularly validated against the disclosure database. ${ }^{37}$ 
How this study could promote better decisions

Decisions on public funding of medicines and treatments are some of the most controversial in healthcare. Involvement of patients complements clinical and economic evidence with the experience of people actually living with the condition in question and is essential to an accurate and fair assessment of the value of new technologies. ${ }^{16}$ Yet if patient perspectives are truly given weight by decision makers, any potential bias must also be taken into account. ${ }^{10}$ Although greater involvement of patients in HTA is an encouraging trend, a sign of effective patient involvement would be for patient organisations to be held to disclosure standards as robust as those for committee members. Our study has shown that NICE's policy does not provide decision makers with sufficient information to assess all sources of evidence equally. Our results may be generalisable to other UK policy contexts with patient representation. ${ }^{31}$ For example, clinical commissioning groups are expected to involve patients in local commissioning of services, but this interaction is not covered in conflicts of interest guidance. $^{3839}$

\section{Future research and conclusions}

Our results are likely to be of interest to HTA agencies in other jurisdictions, which may find it useful to replicate this study. Moreover, other agencies may have made sufficient decisions on technologies to investigate the effect of undeclared specific interests on recommendations and may hold more detailed records to undertake qualitative analyses of contributions. We have examined patient organisations here, but the contributions of other stakeholder organisations such as professional associations and research groups would also be of interest. In conclusion, a more robust disclosure framework and greater transparency from patient organisations and manufacturers is needed to sustain the patient's voice in policy and reassure the public that healthcare decisions are not unduly influenced by industry. ${ }^{810}$

We thank all the patient organisations that took time to respond to our questions and provide feedback. We also thank Lizzie Thomas, Chloe Kastoryano, and Victoria Thomas of the Public Involvement Programme and Kevin Harris of the Interventional Procedures Programme, NICE, for their help in accessing data, understanding existing policy, and reviewing drafts of the paper.

Contributors: KLM and HP designed the study. KLM, HP, RB, CS, and AP collected the data. KLM and KY did the analysis. KLM wrote the first draft of the manuscript. All authors reviewed the manuscript. All authors, external and internal, had full access to all of the data (including statistical reports and tables) in the study and can take responsibility for the integrity of the data and the accuracy of the data analysis. The corresponding author attests that all listed authors meet authorship criteria and that no others meeting the criteria have been omitted. KLM is the guarantor.

Funding: No specific funding was received for this study. One author (HP) is an employee of NICE.

Competing interests: All authors have completed the ICMJE uniform disclosure form at www.icmje.org/coi_disclosure.pdf (available on request from the corresponding author) and declare: HP is an employee of NICE, including during the conduct of this study; no other members of NICE had a role in the analysis of data; findings and drafts were shared with NICE to facilitate policy change, but the authors retained editorial control; HP is also the chair of trustees for a local branch of a national patient organisation Mind; Mind asks staff and trustees to adhere to their policy that restricts funding from pharmaceutical companies (full details of the policy can be found at https://www.mind.org.uk/workplace/corporate-partnerships/ guidelines-for-corporate-partners/); KLM undertook a specialty training placement (but was not employed) at NICE before starting this work; no other support from any organisation for the submitted work; no financial relationships with any organisations that might have an interest in the submitted work in the previous three years; no other relationships or activities that could appear to have influenced the submitted work.

Ethical approval: Not needed.

Data sharing: A dataset of all publicly available data used in the study is available from the corresponding author at kate.mandeville@ Ishtm.ac.uk

Transparency: The lead author affirms that the manuscript is an honest, accurate, and transparent account of the study being reported; that no important aspects of the study have been omitted; and that any discrepancies from the study as planned (and, if relevant, registered) have been explained.

This is an Open Access article distributed in accordance with the Creative Commons Attribution Non Commercial (CC BY-NC 4.0) license, which permits others to distribute, remix, adapt, build upon this work non-commercially, and license their derivative works on different terms, provided the original work is properly cited and the use is noncommercial. See: http://creativecommons.org/licenses/by-nc/4.0/.

1 Abola MV, Prasad V. Characteristics and conflicts of public speakers at meetings of the oncologic drugs advisory committee to the us food and drug administration. JAMA Intern Med 2016;176:389-91. doi:10.1001/jamainternmed.2015.7805

2 McCoy MS, Carniol M, Chockley K, Urwin JW, Emanuel EJ, Schmidt H. Conflicts of Interest for Patient-Advocacy Organizations. N Engl] Med 2017;376:880-5. doi:10.1056/NEJMsr1610625

3 Rose SL, Highland J, Karafa MT, Joffe S. Patient advocacy organizations, industry funding, and conflicts of interest. JAMA Intern Med 2017:177:344-50. doi:10.1001/jamainternmed. 2016.8443

4 Lin DH, Lucas E, Murimi IB, Kolodny A, Alexander GC. Financial conflicts of interest and the centers for disease control and prevention's 2016 guideline for prescribing opioids for chronic pain. JAMA Intern Med 2017;177:427-8. doi:10.1001/ jamainternmed.2016.8471

5 Perehudoff K, Alves TL. Patient and consumer organisations at the European Medicines Agency: Financial disclosure and transparency. Health Action International, 2010.

6 Lo B, Field M, eds. Conflict of interest in medical research, education, and practice. National Academies Press, 2009.

7 Rose SL. Patient advocacy organizations: institutional conflicts of interest, trust, and trustworthiness. J Law Med Ethics 2013;41:680-7. doi:10.1111/ilme.12078

8 Jones K. In whose interest? Relationships between health consumer groups and the pharmaceutical industry in the UK. Sociol Health Illn 2008;30:929-43. doi:10.1111/j.1467-9566.2008.01109.x

9 Abelson J, Giacomini M, Lehoux P, Gauvin FP. Bringing 'the public' into health technology assessment and coverage policy decisions: from principles to practice. Health Policy 2007;82:37-50. doi:10.1016/j. healthpol.2006.07.009

10 Menon D, Stafinski T. Role of patient and public participation in health technology assessment and coverage decisions. Expert Rev Pharmacoecon Outcomes Res 2011;11:75-89. doi:10.1586/erp.10.82

11 Whitty JA. An international survey of the public engagement practices of health technology assessment organizations. Value Health 2013;16:155-63. doi:10.1016/j.jval.2012.09.011

12 Kreis J, Schmidt H. Public engagement in health technology assessment and coverage decisions: a study of experiences in France, Germany, and the United Kingdom. J Health Polit Policy Law 2013:38:89-122 doi:10.1215/03616878-1898812

13 Health Technology Assessment International. Good practice examples of patient and public involvement in health technology assessment. 2015. https://htai.org/wp-content/uploads/2018/02/ Good_Practice_Examples_Feb_2015.pdf.

14 Gauvin FP, Abelson J, Giacomini M, Eyles J, Lavis JN. Moving cautiously: Public involvement and the health technology assessment community. Int I Technol Assess Health Care 2011;27:43-9. doi:10.1017/S0266462310001200

15 Health Technology Assessment International. Values and standards for patient involvement in HTA. 2014. https://htai.org/interestgroups/pcig/values-and-standards/.

16 Gagnon M-P, Desmartis M, Lepage-Savary D, et al. Introducing patients' and the public's perspectives to health technology assessment: A systematic review of international experiences. Int J Technol Assess Health Care 2011;27:31-42. doi:10.1017/ S0266462310001315 
17 Hailey D, Nordwall M. Survey on the involvement of consumers in health technology assessment programs. Int J Technol Assess Health Care 2006;22:497-9. doi:10.1017| S0266462306051427

18 Hailey D, Werkö S, Bakri R, et al. Involvement of consumers in health technology assessment activities by Inahta agencies. Int J Technol Assess Health Care 2013;29:79-83. doi:10.1017/ S026646231200075X

19 National Institute for Health and Care Excellence (NICE). NICE Charter 2017. NICE, 2017.

20 National Institute for Health and Care Excellence (NICE). Policy on declaring and managing interests for NICE advisory committees. Also includes witnesses, expert commentators and other contributors. 2018. https://www.nice.org.uk/Media/Default/About/Who-we-are/ Policies-and-procedures/declaration-of-interests-policy.pdf.

21 National Institute for Health and Care Excellence (NICE). Full list of all published technology appraisal guidance recommendations. 2017.https://www.nice.org.uk/about/what-we-do/our-programmes/ nice-guidance/nice-technology-appraisal-guidance/summary-ofdecisions.

22 National Institute for Health and Care Excellence (NICE). Cancer Drugs Fund. 2018. https://www.nice.org.uk/about/what-we-do/ourprogrammes/nice-guidance/nice-technology-appraisal-guidance/ cancer-drugs-fund.

23 The Prescription Medicines Code of Practice Authority. ABPI Code of Practice for the Pharmaceutical Industry 2016. Prescription Medicines Code of Practice Authority (PMCPA), 2016.

24 Canadian Agency for Drugs and Technologies in Health (CADTH) CADTH Common Drug Review Patient Input. 2018 https://www. cadth.ca/about-cadth/what-we-do/products-services/cdr/patientinput.

25 Scottish Medicines Consortium (SMC). Patient Group Partners. 2018 https://www.scottishmedicines.org.uk/about-us/public-involvement/ patient-group-partners/.

26 Frybourg S, Remuzat C, Kornfeld A, Toumi M. Conflict of interest in Health Technology Assessment decisions: case law in France and impact on reimbursement decisions. J Mark Access Health Policy 2015;3:25682. doi:10.3402/jmahp.v3.25682

27 Piller C, You J. Hidden conflicts? Pharma payments to FDA advisers after drug approvals spark ethical concerns. Science 2018;2018. doi:10.1126/science.aau6842.
28 Arie S, Mahony C. Should patient groups be more transparent about their funding?BM/ 2014;349:g5892. doi:10.1136/bmj.g5892

29 Mulinari S, Ozieranski P. Disclosure of payments by pharmaceutical companies to healthcare professionals in the UK: analysis of the Association of the British Pharmaceutical Industry's Disclosure UK database, 2015 and 2016 cohorts. BMJ Open 2018;8:e023094. doi:10.1136/bmjopen-2018-023094

30 Hawkes N. Doctors getting biggest payments from drug companies don't declare them on new website. BMJ 2016;354:i3679. doi:10.1136/bmj.i3679

31 Baggott R, Jones K. The voluntary sector and health policy: the role of national level health consumer and patients' organisations in the UK. Soc Sci Med 2014;123:202-9. doi:10.1016/j. socscimed.2014.07.016

32 PLoS Medicine Editors. Making sense of non-financial competing interests. PLoS Med 2008:5:e199. doi:10.1371/journal. pmed.0050199

33 Newton A, Lloyd-Williams F, Bromley H, Capewell S. Food for thought? Potential conflicts of interest in academic experts advising government and charities on dietary policies. BMC Public Health 2016;16:735. doi:10.1186/s12889-016-3393-2

34 Scottish Medicines Consortium. Capturing the patient and carer voice. 2017. http://www.scottishmedicines.org.uk/Public Involvement/ Public_Involvement

35 Scottish Medicines Consortium. Nivolumab $10 \mathrm{mg} / \mathrm{mL}$ concentrate for solution for infusion (Opdivo $($ )). SMC No (1240/17). Scottish Medicines Consortium, 2017

36 Santos Al. The Sun Shines on Europe: Transparency of financial relationships in the healthcare sector. Health Action International, 2017.

37 Haute Autorité de Santé. Rapport annuel du déontologue de la Haute Autorité de Santé (Article L.1451-4 du code de la santé publique). Saint-Denis-La Plaine Haute Autorité de Santé, 2018.

38 NHS England. Patient and public participation in commissioning health and care: Statutory guidance for CCGs and NHS England. NHS England, 2017.

39 NHS England. Managing conflicts of interest: Revised statutory guidance for CCGs 2017. NHS England, 2017.

Supplement: Expert nomination form in use during study period 